\title{
The role of teleoaffective profiles in practice adaptation
}

Fiona Spotswood (corresponding author: fiona.spotswood@,bristol.ac.uk), School of Management, University of Bristol, Orcid: 0000-0003-1223-2012

James Steele, Faculty of Sport, Health and Social Sciences, Solent University

Patrokolos Androulakis-Korakkakis, Faculty of Sport, Health and Social Sciences, Solent University

Alex Lucas, Senior Research Analyst, UKactive

Please cite as: Spotswood, F., Steele, J., Androulakis-Korakakis, P., \& Lucas, A. (2021, December 15). The role of teleoaffective profiles in practice adaptation. https://doi.org/10.31235/osf.io/ug $4 \mathrm{kq}$

\section{Acknowledgement}

We would like to acknowledge the tremendous contributions of all the authors involved with the original international survey study that led to the ability to complete this current project. Without their efforts it would not have been possible. They are: James Fisher, Luke Carlson, David Williams, Stuart Phillips, Dave Smith, Brad J. Schoenfeld, Jeremy P. Loenneke, Richard Winett, Takashi Abe, Stéphane Dufour, Martino V. Franchi, Fabio Sarto, Tommy R. Lundberg, Paulo Gentil, Thue Kvorning, Jürgen Giessing, Milan Sedliak, and Antonio Paoli. Further, we would like to acknowledge the contribution of Milo Wolf and Nick 


\begin{abstract}
Consumer research is interested in the way consumers navigate consumption in the face of disruption, often using practice theory to focus on how practitioners creatively realign practice elements in order to carry on. Although recognising their significance, this research undertheorizes the significance, role and characteristics of 'meanings' in practice adaptation, presenting them as constraining and yet easy to adapt. We explore and theorize meanings in practice adaptation by mobilising the theoretical leverage of Schatzki's (2002) concept of 'teleoaffective structures'. Through our empirical material, we illuminate how multifaceted teleoaffective components constituent of teleoaffective structures are integrated differently into routinised practice performances in relatively stable ways; incorporated via 'teleoaffective profiles' that are unique to practitioners but properties of practices. Furthermore, we propose that teleoaffective profiles have different characteristics that condition practice adaptation, as teleological orientations and affective engagements afford different pathways towards integration with available materials and competences. We use our empirical material, based on interviews with loyal gym-based resistance training practitioners during COVID-19 gym closures, to illuminate our argument that practitioners can have 'rigid', 'elastic' or 'fluid' teleoaffective profiles. The characteristics of these profiles, which are unique but remain the properties of the practice, mean that adaptation processes and experiences unfold differently. This perspective advances from accounts of adaptation that are centred on binary outcomes of success or failure. Furthermore, our theorization advances from practice-oriented consumption adaptation research that foregrounds practitioner creativity and fails to adequately incorporate understandings of how practice elements condition adaptation processes. Yet, we retain practitioner experiences in our analysis. Teleoaffective components, profiles and properties provides further theoretical leverage to the practice turn in consumption research and advances the burgeoning focus on the significance of teleoaffective structures in the topographies of practices
\end{abstract}




\section{Introduction}

Consumer research is interested in the way consumers navigate consumption in the face of disruption. Much of this research uses practice theory as a social ontology for exploring disruption to, and adaptation of, everyday practices. In this view, a practice is "a routinised way in which bodies are moved, objects are handled, subjects are treated, things are described and the world is understood" (Reckwitz, 2002, p.250) and consumption is understood as a moment in every practice (Warde, 2005). The practices template comprises elements that are integrated in practice performances, and when disruption occurs, configurations of elements require realignment, reassembly, or reconfiguration (Phipps and Ozanne, 2017; Gonzales-Arcos et al., 2021) so that practitioners might comfortably 'carry on'. There has been a particular focus in recent research on practice adaption as a result of environmental catastrophe (Venugopal et al., 2019), poverty (Mguni et al., 2020), becoming a parent (Thomas and Epp, 2019), divorce (Molander, 2017), the physical separation in families (Epp et al., 2014) and the dramatic disruption caused by the COVID-19 pandemic (Campbell et al., 2021).

Within practice theoretic repertoires, 'meanings' are an important part of the practice template, integrated with materials and competences during practice performance (Shove et al., 2012). Existing adaptation research highlights how meanings can condition practice adaptation efforts, such as the meanings of convenience in using plastic bags for shopping that constrain consumers shifting to reusable bags (Gonzales-Arcos et al., 2021); meanings of cleanliness and hygiene or aesthetically pleasing gardens that make adapting to drought conditions difficult (Phipps and Ozanne, 2017); the moral legitimacy of traditional livelihood practices that constrain adaptation to modern fishing practices in the face of environmental catastrophe (Venugopal et al, 2019); or the 'core' meanings of family meal times that must sustain even when other elements are radically adapted to cope with family separation (Epp et al., 2014). However, we know little about the characteristics of meanings in how they condition practice adaptation processes and experiences, and the focus of existing research tends to be on practitioner striving to realign practice elements to carry on (Thomas and Epp, 2019). Previous research has particularly overlooked the range of meanings offered by the practice template, the dynamics of how these are integrated into routinised practice performances, and their significance in practice adaptation. Our research therefore seeks to theorize the significance, characteristics, and role of meanings in the dynamics of practice adaptation triggered by disruption.

With this article, we explore and theorize meanings in practice adaptation by mobilising the theoretical leverage of Schatzki's (2002) concept of 'teleoaffective structures'. Existing practice adaptation research tends to employ the 'three elements' model of practices, which "collapses" the "tricky territory" of motivation, emotion, purpose, and end goals in routine consumption practices into the simplified 'meanings' element (Shove et al., 2012, p.23). As a result, the intricacy of the 'sense of orientation to particular goals and ends', the 'emotions' and 'motivational engagements' (Schatzki, 2002) that form a major topography for practice enactment and adaptation becomes obscured. Through our empirical material, we illuminate how multifaceted components constituent of teleoaffective structures are integrated differently into routinised practice performances in relatively stable ways; incorporated via 'teleoaffective profiles' that are unique to practitioners but properties of 
practices. Furthermore, we propose that teleoaffective profiles have different characteristics that condition practice adaptation, as teleological orientations and affective engagements afford different pathways towards integration with available materials and competences. We use our empirical material to illuminate our argument that practitioners can have 'rigid', 'elastic' or 'fluid' teleoaffective profiles, and consequently we add to the growing body of research within the social ontology of practice that focuses on disruption and consumer adaptation. We also contribute to the growing body of consumption research interested in exploring how 'teleoaffective structures' can help theorize consumer engagement, defection and adaptation in market-mediated consumption (Erler, Keck and Dittrick, 2020; Molander and Hartman, 2018; Spotswood et al., 2020; Twine, 2017; Welch, 2020).

This article is organised as follows. First, we discern the theoretical underpinnings of practice transition and adaptation in consumer research, positioning our theoretical contribution as drawing on the strengths of each. Second, we expand on the theoretical leverage offered by 'teleoaffective structures' for practice adaptation research and introduce our theorization of teleoaffective profiles through our empirical interrogation of gymbased resistance training (RT) practice adaptation during the COVID-19 pandemic 'lockdowns'. Gym closures during this time meant that practitioners who were accustomed to highly routinised performances in the gym environment needed to adapt to home training to carry on. Lastly, we consider the consequences of our theoretical contributions for future consumption research interested in practice adaptation.

\section{Practice adaptation and meanings}

Research conceptualising the transition or evolution of practices tends to emphasise that they have "something of a life of their own" (Blue et al., 2016: 41) and this approach is merited with a "high degree of deinvidualization" (Molander and Hartman, 2018, p.3) lacking in the cultural turn (Warde, 2005; 2014). In this view, practices are understood as constantly unfolding and inherently dynamic. They evolve, change or disappear as "links between their defining elements are made and broken" (Shove et al., 2012, p.21), and through repeated performances in which elements are recurrently integrated in subtly different ways. This often happens slowly over time (Shove et al., 2012) although new material objects and technologies also trigger change (Hand et al 2005; Pantzar and Ruckenstein, 2015; Shove and Pantzar, 2007). In these practice repertoires, the emphasis is on the characteristics of practice elements and their interconnection that condition consumption transition, and “individual level experiences and emotions" are often rigorously disregarded (Molander and Hartman, 2018, p.3) because individuals are seen predominantly as practice 'carriers' (Reckwitz, 2002).

In contrast, the research focusing on disruption and practice adaptation, on which the present study builds, tends to foreground the way practitioners strive; creatively refining and adapting their performances and bringing practice elements back into alignment with one another in order to carry on. For example, Thomas and Epp's (2019) participant parents responded to disruption "by finding ways to make practices work; they problem-solve, trouble-shoot and try to realign elements” (p.569). For Epp et al (2014), it is consumers’ imaginative capacities that allow consumers "to creatively envision components interacting in a reassembly" 
(Epp et al., 2014, p.88). Gonzalez-Arcos et al. (2021) note the importance of 'sensemaking' as an early stage of practice adaptation, during which practitioners creatively consider the possibilities of substituting materials, meanings, or competences (or all three). Similarly, some of Phipps and Ozanne's (2017) respondent households “reflected on the problem of maintaining a garden and then 'retooled' to expand their water supply by investing in new materials and creating new rainwater management practices" (p.372). Practitioners appear capable of realigning any practice elements necessary for transforming the practice and carrying on, for example through 'microadjustments' to competences, materials or meanings required to establish new water routines (Kadibadiba et al., 2018; Phipps and Ozanne, 2017).

Creative practitioner striving in adaptation is made possible by practices, yet in this view the significance of practice elements and configurations that condition adaptation are obscured. Particularly, we note the lack of theorization of 'meanings' in adaptation processes, which emerge as consistently pivotal; as constraining, requiring protection or easy to shift. For example, Gonzales-Arcos et al. (2021) highlight how associations of convenience inherent to previous configurations of shopping (where plastic bags were readily available), meant the newly enforced adaptation to shopping without plastic bags was sometimes met with disgust. Epp et al. (2014) illuminate that whilst all practice elements are "fluid rather than fixed" (p.83) and can be reassembled in different configurations in the face of disruption, the 'core meanings' of family mealtimes must be retained through the various trajectories of tech-mediated adaptation they identify, otherwise practices will "fail to reassemble" (p.88). Yet, Phipps and Ozanne (2017) suggest that making “micro-adjustments" to meanings of water use practices is unproblematic (p.371), and Molander (2017) notes that challenging associations between 'victim' and divorce can readily be challenged.

There is a need for further attention to be paid to the dynamic role of meanings in practice adaptation processes, but without disregarding the perceiving and experiencing consumer. We propose using 'teleoaffective structures' (Schatzki, 1996, 2002) to leverage this theoretical insight. Most practice adaptation research tends to use what Shove et al (2012, p.23) described as the "collapsed" concept of 'meanings' to conceptualise the "social and symbolic significance of participation in any one moment" (ibid) (eg. Epp et al., 2014; Gonzales-Arcos et al., 2021; Kadibadiba et al., 2018; Phipps and Ozanne, 2017; Thomas and Epp, 2019). Theorization of 'meanings' can appear somewhat fixed in this research, yet Schatzki conceptualises teleoaffective structures as multi-faceted, evolving and relational (Reckwitz, 2017). They include:

"a range of acceptable or correct ends, acceptable or correct tasks to carry out for these ends, acceptable or correct beliefs (etc.) given which specific tasks are carried out for the sake of these ends, and even acceptable or correct emotions out of which to do so" (Schatzki, 2001, p.53).

Crucially, teleoaffective structures are also integrated into performances differently, because people are affected in diverse, 'uneven' (Schatzki, 2002) ways by things and ideas, depending on the unique configurations of practice that organise their everyday lives. This affords a more nuanced understanding of the 'life' of meanings in practice adaptation. 
Mobilising the full theoretical leverage of teleoaffective structures, we demonstrate through the following empirical analysis that the way teleoaffective structures of RT are integrated into routinised practice performances is contextual, and varies amongst practitioners. Furthermore, practitioners connect with a fairly stable profile of teleoaffective components made available by, and which remains the property of, the teleoaffective structure of the practice. These teleoaffective profiles are unique, but share patterns of characteristics that we call 'rigid', 'fluid', and 'elastic'. These condition how modified practice elements (materials and competences) can be integrated, and how the adapted practice of RT is experienced and proceeds in the face of disruption.

\section{COVID-19 disruptions to gym-based resistance training}

Our context is gym-based RT practices, which were severely disrupted during gym closures in The United Kingdom (UK) during the first lockdown, in the height of the COVID-19 pandemic. Modern RT emphasises the utilisation of equipment and materials for the purposes of enhancing strength, and today forms a key component of physical activity guidelines for health worldwide (Bull et al., 2020). Consumer culture has developed varied forms of RT practices, including strength sports like powerlifting, Olympic weightlifting, bodybuilding and CrossFit. All are most often gym-based due to the need for specialist equipment.

In early 2020, the onset of the COVID-19 global pandemic and consequent 'social distancing' measures resulted in the temporary, and in some cases extended, global closure of many gyms and leisure facilities (amongst other services and amenities as part of wider measures); colloquially referred to as 'lockdown'. As such, the practices of millions of gym members were disrupted. In the UK, public and private gyms and leisure facilities were closed on $20^{\text {th }}$ March 2020, reopened in Northern Ireland on $10^{\text {th }} \mathrm{July}$, in England on $25^{\text {th }} \mathrm{July}$, Wales on $10^{\text {th }}$ August and Scotland on $31^{\text {st }}$ August. After various closures due to a brief 'tier' system founded on infection rate variability, a second lockdown, starting $31^{\text {st }}$ October 2020, forced gym closure in England for the month of November, and again across the UK from $20^{\text {th }}$ December. Full lockdowns from Christmas across the UK meant that gyms did not eventually reopen until $12^{\text {th }}$ April 2021 after over a year of intermittent disruption (ukactive, 2021). Despite the importance of gyms for RT performance, results from a global quantitative study (redacted) revealed that a majority of regular RT practitioners were able to adapt and continue at home (82.8\%), although there was a reduction in perceived effort, effectiveness and enjoyment, and higher risks of defection.

\section{Empirical material and methods}

The empirical material we use to develop our theorization of teleoaffective profiles was collected in the UK in 2020/21 during the series of lockdowns and gym closures. Interviewees were recruited from a volunteer pool via the UK survey led by the second author (redacted), from which a purposive sample of participants was selected for maximum variation. The sample included a mix of sexuality, ethnicity, gender, life stage, age, family structure, working status and RT status. As table 1 illustrates, participants reported a range of pre-pandemic modes of engagement in RT, a range of available home training equipment during lockdowns, varied reasons for training and differing adaptation outcomes. 
Initially, online semi-structured interviews with 22 regular, loyal RT practitioners were conducted in June/July 2020. Practitioners all trained between three and six times per week, and had been training between 1 and 25 years. Thirteen follow-up interviews were conducted online in March/April 2021, where participants were willing. First interviews lasted around 65 minutes, and follow-up interviews around 55 minutes. Interview dates coincided with planned reopening of gyms in July 2020 and April 2021. The study received ethical approval and careful data privacy and consent procedures, in line with ethics and General Data Protection Regulations (GDPR), were followed. 
Table 1: Sample table

\begin{tabular}{|c|c|c|c|c|c|c|c|}
\hline \multirow{2}{*}{$\begin{array}{l}\text { Pseudony } \\
\mathrm{m} \\
\text { Loraine }\end{array}$} & \multicolumn{2}{|c|}{ Demographic and personal details } & \multirow{2}{*}{$\begin{array}{l}\text { Available equipment and space in lockdown } \\
\text { House with small patio and garden. Barbell and basic } \\
\text { equipment available at home. }\end{array}$} & \multirow{2}{*}{$\begin{array}{l}\text { RT modality and experience } \\
\text { General RT for martial arts, 6yrs }\end{array}$} & \multirow{2}{*}{$\begin{array}{l}\begin{array}{l}\text { Self-reported } \\
\text { adaptation outcome }\end{array} \\
\text { Continued at home }\end{array}$} & \multirow{2}{*}{$\begin{array}{l}\text { Teleoaffective state } \\
\text { Elastic/fluid }\end{array}$} & \multirow{2}{*}{$\begin{array}{l}\text { Follow up } \\
\text { interview } \\
\text { yes }\end{array}$} \\
\hline & $\begin{array}{l}\text { Female, } \\
53\end{array}$ & $\begin{array}{l}\text { Single parent, one teenage child. } \\
\text { Continued working part time. }\end{array}$ & & & & & \\
\hline Trevor & $\begin{array}{l}\text { Male, } \\
32\end{array}$ & $\begin{array}{l}\text { Lives with partner, no children. } \\
\text { Furloughed physiotherapist. }\end{array}$ & $\begin{array}{l}\text { Very small house with outdoor space. No equipment. } \\
\text { Then moved to Guernsey where there was no second } \\
\text { lockdown and joined local gym to resume training. }\end{array}$ & $\begin{array}{l}\text { Weight lifting and RT for sports, } \\
14 \mathrm{yrs}\end{array}$ & Defected & Rigid & yes \\
\hline Emma & $\begin{array}{l}\text { Female, } \\
31\end{array}$ & $\begin{array}{l}\text { Married, three children, } \\
\text { continued working throughout. }\end{array}$ & Lives in house. Home gym in garage. & Competitive Olympic Lifter, 10yrs & Continued at home & Rigid/elastic & yes \\
\hline Mark & $\begin{array}{l}\text { Male, } \\
28\end{array}$ & $\begin{array}{l}\text { No children, lives with partner. } \\
\text { Furloughed from job as } \\
\text { physiotherapist. }\end{array}$ & $\begin{array}{l}\text { Small house with outside space, gazebo and barbell and } \\
\text { bench set up. }\end{array}$ & Powerlifting, 10yrs & Continued at home & Rigid & no \\
\hline Adele & $\begin{array}{l}\text { Female, } \\
35\end{array}$ & $\begin{array}{l}\text { Single, no children, worked full } \\
\text { time throughout. }\end{array}$ & $\begin{array}{l}2^{\text {nd }} \text { floor flat, bought } £ 1000 \text { worth of equipment during } \\
\text { lockdown. }\end{array}$ & Powerlifting, 5yrs & Continued at home & Rigid/elastic & no \\
\hline Roger & $\begin{array}{l}\text { Male, } \\
60\end{array}$ & $\begin{array}{l}\text { Married, no children. } \\
\text { Furloughed. }\end{array}$ & Fully kitted out home gym. & General RT, 40yrs & Continued at home & Fluid & yes \\
\hline Rowena & $\begin{array}{l}\text { Female, } \\
51\end{array}$ & $\begin{array}{l}\text { Married, two grown up children. } \\
\text { Furloughed. }\end{array}$ & $\begin{array}{l}\text { Small house with little space but a good range of } \\
\text { equipment, e.g. kettlebells and gymnastic rings. }\end{array}$ & $\begin{array}{l}\text { Competes in strength sports and } \\
\text { martial arts, } 10 \mathrm{yrs}\end{array}$ & Continued at home & Elastic/fluid & no \\
\hline Karen & $\begin{array}{l}\text { Non- } \\
\text { binary, } \\
32\end{array}$ & $\begin{array}{l}\text { Single, no children. Continued } \\
\text { working full time from home. }\end{array}$ & $\begin{array}{l}\text { Shared house with little communal space. A few } \\
\text { dumbbells available. }\end{array}$ & General RT, 1yr & Defected & Elastic/fluid & yes \\
\hline Simone & $\begin{array}{l}\text { Non- } \\
\text { binary, } \\
32\end{array}$ & $\begin{array}{l}\text { Unspecified health problems. } \\
\text { Works part time from home. }\end{array}$ & $\begin{array}{l}\text { Lives in a house with garden, with partner and elderly } \\
\text { mother-in-law. No equipment available at home initially, } \\
\text { but then brought in squat rack and bar, bought more } \\
\text { weights towards end of lockdown. }\end{array}$ & Competes in strength sports, 8yrs & Continued at home & Rigid/elastic & no \\
\hline Lucy & $\begin{array}{l}\text { Female, } \\
38\end{array}$ & Married, one child. & $\begin{array}{l}\text { House with space to train but only } 6 \mathrm{~kg} \text { kettlebell, } \\
\text { resistance bands and gymnastic rings. Bought new barbell } \\
\text { during lockdown. }\end{array}$ & General RT, 5yrs & Continued at home & Rigid & no \\
\hline
\end{tabular}




\begin{tabular}{|c|c|c|c|c|c|c|c|}
\hline Ruth & $\begin{array}{l}\text { Female, } \\
36\end{array}$ & $\begin{array}{l}\text { Married, two children. No paid } \\
\text { work (student). }\end{array}$ & Large house, minimal equipment. & General RT, 8yrs & Defected & Rigid/elastic & no \\
\hline Denis & $\begin{array}{l}\text { Male, } \\
33\end{array}$ & $\begin{array}{l}\text { Single, children (do not live with } \\
\text { him). Furloughed. }\end{array}$ & One bedroom apartment. & Weight lifting, 1yr & Defected & Rigid & yes \\
\hline Caroline & $\begin{array}{l}\text { Female, } \\
\text { over } 60\end{array}$ & Married, no children. & $\begin{array}{l}\text { House and garden. Retired. Home built lifting platform } \\
\text { and garage gym set up. }\end{array}$ & Competitive Olympic Lifter, 4yrs & Continued at home & Elastic & yes \\
\hline Clare & $\begin{array}{l}\text { Female, } \\
40\end{array}$ & $\begin{array}{l}\text { Married, two children. No paid } \\
\text { work (runs house and home). }\end{array}$ & Has kettlebells and resistance bands. & General RT, 1yr & Defected & Rigid/elastic & no \\
\hline Louise & $\begin{array}{l}\text { Female, } \\
21\end{array}$ & Single, no children. Furloughed. & Home gym set up. Lives with parents. & CrossFit, 5yrs & Continued at home & Elastic/fluid & no \\
\hline Vanessa & $\begin{array}{l}\text { Female, } \\
41\end{array}$ & $\begin{array}{l}\text { Married, two children. } \\
\text { Furloughed. }\end{array}$ & $\begin{array}{l}\text { Large house with dedicated gym space. Home gym } \\
\text { equipment borrowed from school. }\end{array}$ & RT for sports, 20 years & Continued at home & Fluid & yes \\
\hline Karim & $\begin{array}{l}\text { Male, } \\
43\end{array}$ & Single, no children. Furloughed. & $\begin{array}{l}\text { Live in a house. Variety of training equipment available } \\
\text { (although nothing heavy). }\end{array}$ & Weight lifting, 20yrs & Continued at home & Fluid & yes \\
\hline Andrea & $\begin{array}{l}\text { Female, } \\
30\end{array}$ & $\begin{array}{l}\text { Lives with partner. No children. } \\
\text { Continued working full time (as } \\
\text { a rugby player). }\end{array}$ & Had weights and bands sent home from the club. & General RT for sports, $10 \mathrm{yrs}$ & Continued at home & Fluid & no \\
\hline Ray & $\begin{array}{l}\text { Male, } \\
39\end{array}$ & $\begin{array}{l}\text { Married, one child. Full time } \\
\text { working from home. }\end{array}$ & $\begin{array}{l}\text { Lives in a house with indoor and outdoor training space. } \\
\text { Minimal equipment including kettlebells, dumbbells and } \\
\text { pullup bars, gymnastic rings. }\end{array}$ & Powerlifting and CrossFit, 3yrs & Defected & Rigid/elastic & yes \\
\hline Dan & $\begin{array}{l}\text { Male, } \\
33\end{array}$ & Single, no children. Furloughed. & Lives in small flat. Minimal equipment at home. & Weight lifting, 5yrs & Defected & Rigid & yes \\
\hline Aaron & $\begin{array}{l}\text { Male, } \\
46\end{array}$ & $\begin{array}{l}\text { Married, three children. Full time } \\
\text { working from home. }\end{array}$ & $\begin{array}{l}\text { Lives in a house with outdoor and indoor training space. } \\
\text { Purchased bar and rack, plus kettlebells and dumbbells } \\
\text { available from workplace gym. }\end{array}$ & Weight lifting, 2yrs & Continued at home & Fluid & Yes \\
\hline Romy & $\begin{array}{l}\text { Female, } \\
39\end{array}$ & $\begin{array}{l}\text { Married, one child. Continued } \\
\text { working part time from home. }\end{array}$ & $\begin{array}{l}\text { Lives in a house with indoor and outdoor space. } \\
\text { Dumbbells and pull up equipment available. }\end{array}$ & Weight lifting, 3yrs & Defected & Fluid & Yes \\
\hline
\end{tabular}


Using a piloted topic guide, first interviews explored everyday RT routines before the pandemic, and experiences of adaptation since. Prior to interviews, participants were invited to email photographs of home training spaces and equipment, which were used to enable deep discussions about lockdown RT adaptation experiences. Given the role of reflexivity in hermeneutic research (Moules et al., 2015), interviewers used their own experiences of RT as the basis for rapport building and probing during interviews as well as gleaning otherwise hidden inferences and meaning from the data. Follow-up interviews occurred after gyms had unexpectedly closed for the second time, and remained closed, and focused more heavily on extended adaptation as well as participant experiences during the brief reopening of gyms.

Interviews were transcribed, anonymised and then analysed using NVIVO12. Following grounded theory procedures, three of the authors initially created open codes from the data without a predefined theoretical framework (Corbin and Strauss, 2008), coding "at the level of the consumption practice" (Epp et al., 2014, p.84) and compared described adaptation outcomes with those self-reported in the survey. Through this analysis, we gained an initial understanding of the RT practices from consumers' perspectives, and identified differences in the way meanings conditioned adaptation. Through an ongoing, iterative process involving back-andforth examination of theory and data (Spiggle, 1994) meaningful constructs were reviewed critically by all authors and member-checked with participants. Axial coding was applied through this iterative engagement with extant literature and theory, focusing on the teleoaffective structures, components, and profiles of RT practices during adaptation.

\section{The role of teleoaffective profiles in practice adaptation}

\section{Teleoaffective profile}

Teleoaffective structures comprise a range of components, which participants could collectively identify as belonging to RT. They recognised RT as offering experiences of mastery, outcomes of strength, an appealing competitive 'mood', and end goals in the form of formal success in competition, in terms of aesthetics or intense physical tiredness. However, participants integrated these components in different ways in relation to their own life histories, current configuration of practices, and priorities (Schatzki, 2002). Practitioners connected with unique 'teleoaffective profiles' in their enactment of RT, which exhibited a hierarchy and distinct shape; some teleoaffective components more important than others. For example, the aesthetic end goal component of RT was recognised as a de facto teleoaffective component of RT as one participant, Karen, pointed out: "With weight training there is the sort of connection to like weight loss and 
aesthetics, you know, like". However, she also 'resists' the allure of aesthetic outcomes, focusing on other components like strength and pain management:

"I think there's sort of an allure to [aesthetics] that I tried to resist because for me it's about being strong, managing pain, being healthy when I'm older and I did enjoy getting more muscular, I did enjoy getting more lean but I also want to resist that as well and you know, it's not about that for me" (Karen, $2^{\text {nd }}$ interview).

Karen's teleoaffective profile includes aesthetics only to a negligible degree. Similarly, Romy largely rejects the aesthetic appeal of RT, describing how she finds it "funny" to "see the girls doing all the squatting and then Instagram their butts..." She is clear that "it's not quite what I'm in there for but you know. It's nice". However, despite both largely rejecting the draw of aesthetics, Karen and Romy connect with other teleoaffective components differently because of their personal histories. Romy enjoys lifting heavy because she's good at it and has found other sports unwelcoming or difficult:

"I find the bar lifting heavy is really empowering. I've struggled so much throughout the years. I'm driven to sport but most sport for women having body types that aren't mine... I'm not built to go beneath a bar bell, but to be 5'2 and workout $100 \mathrm{~kg}$ for reps was great" ( $2^{\text {nd }}$ interview).

In contrast to Romy's experience of empowerment, Karen's teleoaffective profile is coloured by a history of chronic pain, so their resistance of the 'aesthetic' component has different roots.

For another participant, Dan, aesthetics are central to how RT matters for him in the context of his history of mental health battles. He spent his twenties and thirties "in bad places" mentally, then started RT and "put on a stone and a half of muscle mass". He describes beginning to "smile at myself in the mirror". For Dan, the dominant pull of RT is the "transformative nature of it" He admits:

"I can look in the mirror and go, 'actually, you look better'. And you look healthier. Yes, your skin's brighter, you don't look as tired. You look healthier"”.

Other components of Dan's teleoaffective profile included socialising with his "sauna buddies" and warding off the inevitable bodily deterioration of older age, but these were subsidiary. In contrast, throughout her two interviews, Vanessa itemised a range of teleoaffective components that were of equal significance in how, and why, she routinely performed RT: 
"[RT] makes me really happy. It's if I don't train, I think life is harder for me. It just gives me a bit of clarity. It just gives me some headspace. Yeah I think obviously the physical is really important. I like feeling fit. I like feeling strong."

She also likes having people around her while she trains, enjoying the gym environment, and explains the draw of feeling physically exhausted from training. Only towards the end of the second interview did Vanessa mention aesthetics, quipping that 'I'd be lying if I said I didn't think about aesthetics. We all do". Although Vanessa and Dan's profiles both include aesthetic end goals, the component works differently within their unique teleoaffective profiles. Dan's has a dominant central component with subsidiaries; Vanessa's has multiple, evenly prioritised components and subsidiaries.

Disruption and adaptation

All participants could recognise the suite of teleoaffective components made available by the RT template, yet contextualised by their life histories, each practitioner had a unique teleoaffective profile, with components that had different prominence. Furthermore, our analysis found that across the different profiles there were three broad types, and these implicated different experiences and outcomes of practice adaptation. Table 2 illustrates an overview of the different types, described as 'rigid', 'elastic' and 'fluid', and provides empirical examples that will now be explored in full. 
Table 2: Illustrative empirical examples of rigid, elastic and fluid teleoaffective profiles

\begin{tabular}{|c|c|c|c|}
\hline $\begin{array}{l}\text { Teleoaffective } \\
\text { profile }\end{array}$ & Properties of teleoaffective profile & $\begin{array}{l}\text { Impact of profile on } \\
\text { adapted elements }\end{array}$ & Empirical example \\
\hline Rigid & $\begin{array}{l}\text { Dominant component, or small } \\
\text { range of similar components } \\
\text { dominating subsidiary components. } \\
\text { Tight integration of central } \\
\text { components with materials and/or } \\
\text { competences in routinised } \\
\text { performance. }\end{array}$ & $\begin{array}{l}\text { Heavy reliance on } \\
\text { availability of } \\
\text { adapted } \\
\text { competences and } \\
\text { materials needed to } \\
\text { carry on. }\end{array}$ & $\begin{array}{l}\text { Denis: "after about four weeks, I found that [attempted home training] is } \\
\text { complete and total bollocks and is not doing anything for me. Basically, I } \\
\text { started getting very familiar with the couch". } \\
\text { Deis was a 'serious' body builder before lockdown, focused on the technical } \\
\text { proficiency of his performances and the strength outcomes. Without equipment } \\
\text { that replicated that in his gym, no other version of RT was acceptable. }\end{array}$ \\
\hline Elastic & $\begin{array}{l}\text { Teleoaffective profile can flex as } \\
\text { different components can } \\
\text { temporarily take on prominence } \\
\text { while formerly prominent } \\
\text { components temporarily required to } \\
\text { retreat. }\end{array}$ & $\begin{array}{l}\text { Adapted materials } \\
\text { and competences } \\
\text { less central to } \\
\text { adaptation process. }\end{array}$ & $\begin{array}{l}\text { Lorraine: "I tolerated [a shift in focus]. I am going to be happy to get back into } \\
\text { the gym and lifting heavier weights. I'm looking forward to that". } \\
\text { Lorraine was able to focus temporarily on strength gains, but was looking } \\
\text { forward to returning to the intense group training environment of her CrossFit } \\
\text { box. }\end{array}$ \\
\hline Fluid & $\begin{array}{l}\text { Teleoaffective profile includes a } \\
\text { broad range of equally weighted } \\
\text { components. At least some } \\
\text { components are not tightly } \\
\text { integrated with materials in routine } \\
\text { performance. }\end{array}$ & $\begin{array}{l}\text { Minimal reliance on } \\
\text { adapted materials } \\
\text { and competences. }\end{array}$ & $\begin{array}{l}\text { Roger: "I did start doing a bit more running and that sort of thing. I've added a } \\
\text { little bit more exercise, but largely it doesn't really impact me too much. As I } \\
\text { said, I'm quite fortunate with the equipment I've got. I can pretty much carry } \\
\text { on as normal". } \\
\text { Roger had a varied teleoaffective profile, and components were not tightly } \\
\text { integrated with the material environment of his gym in routinised practice. He } \\
\text { found it easy adapting to home training and incorporating a range of adapted } \\
\text { practices. }\end{array}$ \\
\hline
\end{tabular}




\section{Rigid teleoaffective profile}

Some participants connected with characteristically 'rigid' teleoaffective profiles that had a narrow range of teleoaffective components or a dominant set of central components and more minor subsidiary components. Often, teleoaffective components were difficult to separate from materials and/or competences that played a significant part in recursively reconstituting them in the routinised practice prior to lockdown. Before lockdown, Denis was wholly committed to RT, explaining "I probably take this more seriously than I think most people do from a recreational perspective". He found the control he could exert over his progress in body building highly rewarding, and enjoyed the feeling of technical proficiency as he came to master complex physical movements. When lockdown forced his gym to close, he felt devastated: "I've literally had my gym taken away from me and my work taken away from me. I'm not personally someone who copes very well with change". Although he had the knowledge to adapt to home training even with minimal equipment, the reconfigured practice of home RT failed to allow him to integrate his rigid teleoaffective profile, the dominant component of which was tightly connected with the materiality of the gym environment:

"I did some elevated body weight squats off the sofa and press ups sort of like decline press ups off a chair and things like that but these movements do not feel the same and do not feel like they are working as well and you eventually get very, I don't know, like, 'oh well'... it just starts dragging on and on and you beginning to start to really lose all kind of enthusiasm for anything because you just don't feel like it's doing anything"

Without being able to integrate the dominant teleoaffective components of his profile into his practice, Denis defected from RT:

"After about four weeks, I found that [attempted home training] is complete and total bollocks and is not doing anything for me. Basically, I started getting very familiar with the couch".

Denis' teleoaffective profile was dominated by components which were impossible for him to integrate with alternative materials and reconfigured competences. When the gyms reopened, he admitted, "I very much resumed training almost the same as I've been doing before".

Denis' experience of adaptation failure was very similar to Dan's. Although their teleoaffective profiles were starkly different, they shared rigid properties. As already described, Dan trained predominantly with heavy weights to maintain the dramatic aesthetic self-transformation he had 
achieved through RT. Resorting to training with the light weights he had at home during lockdown felt like "flogging a dead horse":

"I've only got two little dumbbells at home and I'm used to like throwing huge weights over my head... You ain't going to get disco tits [prominent pectoral muscles] with a six kilogram weight (laughs)".

Dan became fixated on the date the gyms were due to reopen. He explains, "I needed something to lift... I had put all my eggs in this particular Fourth of July basket”. Although gyms did reopen briefly, the repeated closure sent Dan into a spiral of addictive eating and drinking behaviours. The rigid properties of Denis and Dans' teleoaffective profiles meant they were impossible to carry through to an adapted version of RT.

Rigidity did not guarantee defection when gyms closed. In rare cases, participants were able to integrate rigid teleoaffective profiles into adapted home-based versions of RT practice by satisfactorily replicating the equipment available in the gym, and by dramatically increasing their competences to scaffold the immovable teleoaffective profile. Before the pandemic, Aaron only had light weights at home and went to the nearby gym every morning at 5.30am; "five days a week, no excuses". When lockdown struck, he tried to train at home with the equipment he had but "despite the best of intentions" he felt he was "spinning wheels... just doing lots and lots of reps for the sake of it, but it didn't feel comfortable. It's not where I'm at with it". He likes the "feeling of discomfort" from lifting heavy and is drawn in by the progress he sees in his strength and appearance that comes from regular, committed training. Realising that adaptation with available equipment (materials) and competences was unacceptable, Aaron quickly purchased a squat rack, bench and barbell, and accrued more equipment over the course of the lockdown year when it became available. Concurrently, he has listened to "endless" podcasts and reads articles daily to improve his knowledge of RT programming and efficiency. These material and competence adaptations meant he could integrate them with his rigid teleoaffective profile without compromise. At the time of the second interview, Aaron was back training in the gym and admitted that his training was "very similar to what it was at home" ( $2^{\text {nd }}$ interview).

\section{Elastic teleoaffective profile}

Participants with elastic teleoaffective profiles were able to realign components within their teleoaffective profile sufficiently to help adjust to the demands of practice adaptation, allowing less-than-perfect configurations of materials and competences to be integrated in a way that afforded carrying on. Elasticity was possible because the teleoaffective profile had a number of equally significant core components rather than a dominant one. 
However, the experience of reconfiguring an elastic teleoaffective profile could be uncomfortable, with realignment only possible temporarily before the profile sprang back into its original form. For example, Lorraine continued training at home when her gym closed, describing the experience as "just about tolerable". Her routinised RT prior to lockdown was organised around self-care and wellbeing. A large part of the way she connected with these teleoaffective components was through CrossFit classes and the shared experience of intensity they provided:

"I don't know whether it is being accountable to other people because we are all visible. It's not a big gym. We just have to keep going, whereas at home I know I would have stopped and I would have gone and said hi to the cat or thought 'I should let it out' as you do."

During lockdown, Lorraine's motivation dwindled and she discovered that it was impossible for her to integrate RT practice elements in the same way at home to recreate the intensity she enjoyed. She persevered by realigning her teleoaffective profile and focusing on strength, a preexisting goal of her RT but formerly subsidiary. This shift in focus was made possible because she bought a barbell and weights, which did not recreate the original practice for her, but made her adapted version temporarily tolerable. She describes the change in terms of the HR zones she achieved (where 'red' is the highest effort, 'green' is medium and 'yellow' the easiest):

"At the gym both before and after the lockdown easing, I'd been 'red' quite a lot. Whereas here, I was mainly 'greens', 'yellows', and only occasionally 'red'. But that was fine. It was it was maintenance rather than improvement I was aiming for here... yeah, it was strength building. It's, it's muscle, its strength that I was working on really".

The interviewer asked Lorraine "And how have you found the shift in focus?", to which she responded, "Um, I tolerated it. I am going to be happy to get back into the gym and lifting heavier weights. I'm looking forward to that".

Other participants had elastic teleoaffective profiles which allowed them to manage the realignment work necessary to carry on, albeit temporarily and uncomfortably. Adele took a long time to adapt to home training. Before lockdown, she connected with the sense of progression she enjoyed through her committed training, but also enjoyed the feeling of expertise as a knowledgeable RT practitioner and personal trainer. At home, she found it difficult to replicate the "tension" she was accustomed to from training at her "highly elite gym". Eventually she 
managed to reconfigure her teleoaffective profile by demoting the importance of progression and instead prioritising the satisfaction afforded by knowing how to adapt to home training:

"I've slowly started to enjoy training more again, almost like week by week. I'm starting to look forward to it now and it's not it's not just something that I just forced myself to do now. I am slowly getting better at adapting and accepting it now - I'm accepting the new challenge. It's taking a while to accept it I didn't, I didn't like it before; it was it was very hard to accept it. It's just it was very stressful for me at the time".

An elastic teleoaffective profile means practitioners are able to realign the hierarchy of teleoaffective components in order to connect with available materials and competences in a way that means they can be retained to the practice. This is easier if there is a broader range of components and if none dominates overwhelmingly.

Elastic profiles did not guarantee successful adaptation, particularly if materials and competences were not available, as the integration of all practice elements is necessary for performance. Karen, for example, trained at her local gym and came to enjoy the feeling of expertise, the camaraderie with other female lifters, and particularly the strength improvements she was making, although the health benefits for her arthritis also remained important. Due to her elastic teleoaffective profile, Karen was able to realign these components during lockdown, focusing on pain management whilst knowing her strength would diminish and that camaraderie was impossible:

"And so first, I wanted to... try and avoid losing as much muscle mass as possible during lockdown. I was doing more upper body exercises. But that kind of became less important to me, like I just decided I didn't really care so much. And, and the main motivation just became not being not having knee pain"

However, despite realigning her teleoaffective profile, Karen had minimal equipment and very little space, finding it hot and cramped training in her bedroom:

"I wasn't enjoying it [the training] so the number of times I was exercising reduced: the number of sets I was doing reduced, until I just stopped at some point. I gave up... I was trying to do like 100 lunges or something and I just couldn't maintain that" ( $2^{\text {nd }}$ interview).

Necessary materials were not available to Karen to integrate with the reconfigured teleoaffective profile and after a few weeks she defected. 


\section{Fluid teleoaffective profile}

Analysis identified that some teleoaffective profiles had fluid components that could easily be integrated with available materials and competences to carry on with adapted RT. In routinised practice performances, fluid teleoaffective components were only loosely integrated with the material conditions of routinised gym-based RT and there were often a number of equally significant components that practitioners connected with in highly adaptable performances. Roger's teleoaffective profile exemplifies fluidity:

"I know enough now that I can change it up quite easily and still get the results that I want and keep it more interesting" (2nd interview).

A personal trainer, Roger had a well-equipped home gym, and connected with teleoaffective components that varied from achieving fitness and health end goals to facilitating socialising, to satisfaction from his proficiency. Even before lockdown he would effortlessly "switch it up a bit", training at home or in the gym depending on circumstance. Furthermore, he routinely maintained a balance between types of RT, including heavy weights, bodyweight exercises and cardiovascular training, and this variety remained when the gyms closed. He explained his experience self-consciously, aware how unusually easy he found adapted RT during lockdown:

"I did start doing a bit more running and that sort of thing. I've added a little bit more exercise, but largely it doesn't really impact me too much. As I said, I'm quite fortunate with the equipment I've got. I can pretty much carry on as normal" ( $2^{\text {nd }}$ interview).

Roger's motivations, goals, purpose and affective orientations are varied, largely non-hierarchical and not tightly connected with the gym environment. RT practice adapted easily.

To a similar extent, Vanessa has an extensive list of equally significant teleoaffective components from RT practice with which she connects, including intensity from training with others in the gym. Although she missed this environment during lockdown, she adapted her RT training with online classes. These were sufficient for her to feel satisfyingly "broken", another of her key teleoaffective components, or in Vanessa's words, "part of the fix for me". Notably, Vanessa had weightlifting equipment but did far less RT than before lockdown. Rather, some of her fluid teleoaffective components were repurposed; integrated in competing practices like circuit training and running:

"I loved the gym environment. I missed it through the first lockdown but I feel like I've replaced it now doing the outdoor circuits and running with a friend instead. I think I'm getting that social angle that I needed" (2nd) 
The fluidity characterising Vanessa's profile conditioned the ways adaptation was made possible during the pandemic, offering a range of integration opportunities to allow her goals to be met.

\section{Discussion}

We have illuminated the unique ways that practitioners connect with teleoaffective components available in the practice template of RT, which we call their 'teleoaffective profiles'. These profiles become settled through repetition, trial, and progression through the practice career. Although dynamism and change are always a possibility in practices (Warde, 2005), affective and teleological orientations stabilise as they are experienced, embodied, and anticipated (Molander and Hartman, 2018). Furthermore, teleoaffective profiles are configured with different overarching structures; some with single, central components that dominate all others, some with a range of equally significant components and other subsidiaries, and some with a largely nonhierarchical structure. It is recognised that teleoaffective structures are "hierarchically ordered" (Welch, 2020, p.80), but our analysis suggests we can extend this to teleoaffective profiles. Finally, we have illuminated that there are three broad types of teleoaffective profile, relating to these different configurative properties. We call these 'rigid', 'elastic' and 'fluid'.

Rigid teleoaffective profiles comprise a dominant component, and often components that are tightly integrated with materials or competences in the routinised, pre-disruption practice. For adaptation, substantially reconfigured materials and competences are required to replicate the routinised practice, and where near-replication is not possible, defection is likely. Elastic teleoaffective profiles mean teleoaffective components can be realigned to facilitate integration with available or adapted materials and competences, but the experience of adaptation may be only temporarily tolerated. Fluid teleoaffective profiles mean that equally-weighted teleoaffective components are 'free floating' in the routinised practice; only loosely integrated with other elements. They are readily integrated with available competences and materials into an adapted version of the practice, or might as readily "take on a new lease of life within and as part of other practices" (Shove et al., 2012, p.35), resulting in defection.

Our theorization of teleoaffective profiles makes a number of contributions to consumption research interested in theorizing practice adaptation. First, we advance from the limited theorization of meanings in existing accounts, which recognise their significance yet has not sufficiently theorized their role. Particularly, extant research conceptualises meanings as somewhat static and singular across performances, because the "collapsed" concept of meanings (Shove et al., 2012) obscures the intricacies of how teleological orientations and affective engagements become integrated in practice performances and subsequently condition adaptation. 
We contend that the theoretical leverage afforded by Schatzki's (2001) 'teleoaffective structures' usefully illuminates the variability and relationality of meanings. Schatzki (2002) emphasises the expanded "collection" (p.80) of teleoaffective components and how they are integrated into performances variably, because people are affected in diverse, 'uneven' ways by things and ideas, depending on the unique configurations of practice that organise their everyday lives and on their personal histories. This interpretation has been noted in other consumption research, such as Plessz and Gojard (2015, p.4), who emphasise differences in degrees of commitment and modes of engagement between practitioners enacting cooking practices depending "how they connect to the teleoaffective structure of the practice".

Second, our theorization of teleoaffective profiles holds implications for the ontological emphasis in extant practice adaptation research that tends to foreground the creativity of the practitioner in realigning elements and 'carrying on'. We argue that there are conceptual benefits to both de-individualised accounts of practice transition and experience-oriented accounts of practice adaptation. Teleoaffective profiles comprise components that remain the property of practices (Reckwitz, 2017; Welch, 2020), but which relate to the way that unique and experiencing practitioners enact and adapt performances that matter. Our model reenforces that people "in different situations do the same activity differently" (Thomas and Epp, 2019), and piece together constitutive elements of practices in unique ways (Warde, 2005). Thus, we argue that teleoaffective profiles are unique, but bounded by the topography of the practice template (Molander and Hartman, 2018). As such, the critical, individual-level, experiential aspects of practice performances become more central in our account, but practices as 'open-ended' templates (Schatzki, 1997) remain the 'unit of enquiry' (Warde, 2005). This allows for practice adaptation research that accounts for more than binary outcomes of adaptation, as characterises existing research (e.g. Phipps and Ozanne, 2017, Thomas and Epp, 2019). Rather, it enables a focus on the dynamic interactions between teleoaffectivity, adaptation processes and practitioner experience.

To conclude, we argue that teleoaffective components, profiles and properties provides further theoretical leverage to the practice turn in consumption research and advances the burgeoning focus on the significance of teleoaffective structures in the topographies of practices (Erler, Keck and Dittrick, 2020; Molander and Hartman, 2018; Spotswood et al., 2020; Twine, 2017; Welch, 2020). To this end, we hope to invigorate a future stream of research that further considers the role of marketing in shaping teleoaffective structures and in providing solutions to consumption problems associated with disruption that relate specifically to different types of teleoaffective profile. 


\section{References}

Bull FC, Al-Ansari SS, Biddle S, et al. (2020) World Health Organization 2020 guidelines on physical activity and sedentary behaviour. British Journal of Sports Medicine 54: 1451-1462.

Campbell MC, Inman JJ, Kirmani A and Price L (2020) In times of trouble: A framework for understanding consumers' responses to threats, Journal of Consumer Research 47: 311-326.

Corbin J and Strauss A, (2008) Strategies for Qualitative Data Analysis. In: Strauss A (ed) Basics of Qualitative Research (3rd ed.): Techniques and Procedures for Developing Grounded Theory: London: SAGE, pp. 57-85.

Epp A, Schau HJ and Price L (2014) The role of brands and mediating technologies in assembling long-distance family practices. Journal of Marketing 78: 81-101.

Erler M, Keck M and Dittrich C (2020) The changing meaning of millets: Organic shops and distinctive consumption practices in Bengaluru, India. Journal of Consumer Culture. Epub ahead of print 27 January 2020.

Fischer E, Otnes CC and Tuncay L (2007) Pursuing parenthood: Integrating cultural and cognitive perspectives on persistent goal striving. Journal of Consumer Research 34(4): 425-440.

Gonzales-Arcos C, Joubert AM, Scaraboto D, Guesalaga R and Sandberg J (2021) "How Do I Carry All This Now?” Understanding Consumer Resistance to Sustainability Interventions. Journal of Marketing 85(3): 44-61.

Halkier B (2009) Suitable cooking? Performances and positionings in cooking practices among Danish women. Food, Culture and Society 12(3): 357-377.

Halkier B, Katz-Gerro T, and Martens L (2011) Applying practice theory to the study of consumption: Theoretical and methodological considerations. Journal of Consumer Culture. 11(1): 313.

Hand M, Shove E and Southerton D (2005) Explaining showering: A discussion of the material, conventional, and temporal dimensions of practice. Sociological Research Online 10(2): 101-113.

Kadibadiba T, Roberts L and Duncan R (2018) Living in a city without water: A social practice theory analysis of resource disruption in Gaborone, Botswana. Global Environmental Change 53: 273-285. 
Mguni P, van Vliet B, Spaargaren G, Nakirya D, Osuret J, Isunju JB, Ssekamatte T and Mugambe R (2020) What could go wrong with cooking? Exploring vulnerability at the water, energy and food Nexus in Kampala through a social practices lens. Global Environmental Change 63(102086).

Molander S (2017) Not just a mother: embodied and positioning aspects of consumer learning from a practice perspective. Consumption Markets and Culture 2: 131-152.

Molander S and Hartmann B (2018) Emotion and practice: Mothering, cooking, and teleoaffective episodes. Marketing Theory 18(3): 371-90.

Moules NJ, McCaffrey JP, Field JC and Laing CM (2015) Conducting hermeneutic research: From philosophy to practice. New York, NY: Peter Lang.

Pantzar M and Ruckenstein M (2015) The heart of everyday analytics: Emotional, material and practical extensions in self-tracking market. Consumption Markets and Culture 18(1): 92-109.

Phipps M and Ozanne J (2017) Routines disrupted: Reestablishing security through practice alignment. Journal of Consumer Research 44(2): 361-80.

Plessz M and Gojard S (2015) Fresh is best?: Social position, cooking, and vegetable consumption in France. Sociology 49(1): 172-190.

Reckwitz A (2002) Toward a theory of social practices: A development in culturalist theorizing. European Journal of Social Theory 5(2): 243-263.

Reckwitz A (2017) Practices and their affects. In: Hui A, Schatzki T and Shove E (eds) The nexus of practices: Connections, constellations, practitioners. New York: Routledge, pp. 114-125.

Schatzki TR (1996) Social practices: A Wittgensteinian approach to buman activity and the social. Cambridge: Cambridge University Press

Schatzki T (2001) Practice minded orders. In: Schatzki T, Cetina KK and von Savigny E (eds) The Practice Turn in Contemporary Theory. London, UK: Routledge, pp. 42-56.

Schatzki T (2002) The Site of the Social. University Park, PA: Penn State University Press

Shove E and Pantzar M (2007) Recruitment and reproduction: The careers and carriers of digital photography and floorball. Human Affairs 17: 154-167.

Shove E, Pantzar M and Watson M (2012) Dynamics of Social Practice. London: Sage. 
Spiggle S (1994) Analysis and interpretation of qualitative data in consumer research. Journal of Consumer Research 21(3): 491-503.

Spotswood F, Shankar A and Piwek L (2020) Changing emotional engagement with running through communal self-tracking: The implications of 'teleoaffective shaping' for public health Sociology of Health and Illness 42(4): 772-788.

Redacted reference to large scale study

Thomas TC and Epp AM (2019) The best laid plans: Why new parents fail to habituate practices. Journal of Consumer Research 46(3): 564-589.

Twine R (2017) A practice theory framework for understanding vegan transition. Animal Studies Journal 6(2): 192-224.

ukactive (2021) Coronavirus (COVID-19): Advice and guidance for the physical activity sector. Available at: https://www.ukactive.com/covid-19/(accessed 28 November 2021).

Venugopal S, Gau R, Appau S, Sample KL and Pereira RCF (2019) Adapting traditional livelihood practices in the face of environmental disruptions in subsistence communities. Journal of Business Research 100: 400-409.

Warde A (2005) Consumption and theories of practice. Journal of Consumer Culture 5(2): 131-153. Warde A (2014) After taste: Culture, consumption and theories of practice. Journal of Consumer Culture 14(3): 279-303.

Welch D (2020) Consumption and teleoaffective formation: Consumer culture and commercial communications. Journal of Consumer Culture 20(1): 61-82. 